Supplement of Atmos. Chem. Phys. Discuss., 15, 21449-21494, 2015

http://www.atmos-chem-phys-discuss.net/15/21449/2015/

doi:10.5194/acpd-15-21449-2015-supplement

(C) Author(s) 2015. CC Attribution 3.0 License.

(c) (1)

\title{
Distinguishing the drivers of trends in land carbon fluxes and plant volatile emissions over the past three decades
}

X. Yue et al.

Correspondence to: X. Yue (xuyueseas@gmail.com)

The copyright of individual parts of the supplement might differ from the CC-BY 3.0 licence. 
(a) Trend of GPP

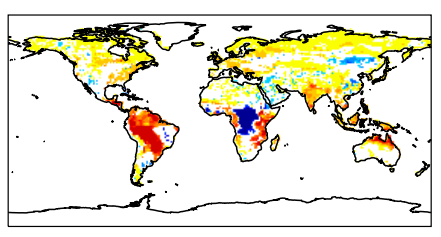

(b) Trend of NPP

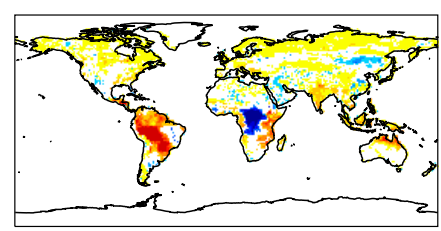

(c) Trend of NEP

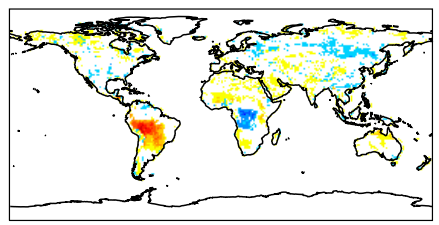

20

$30 \quad\left(\mathrm{~g} \mathrm{~m}^{-2} \mathrm{a}^{-2}\right)$ (d) Drivers of GPP trend

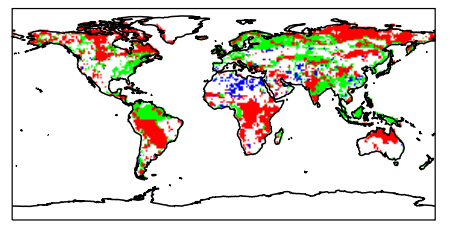

Meteorological forcing (e) Drivers of NPP trend

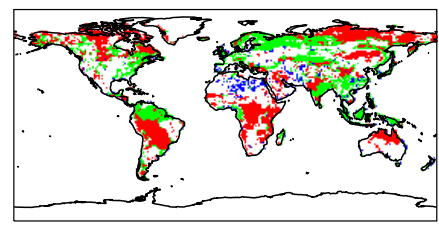

CO2 fertilization (f) Drivers of NEP trend

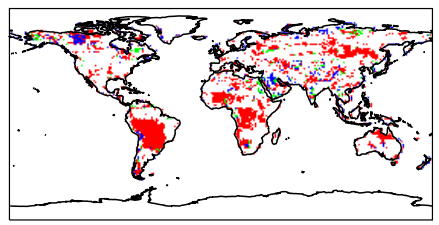

Land use change

Figure S1. Simulated trend in (a) gross primary productivity (GPP), (b) net primary productivity (NPP), and (c) net ecosystem productivity (NEP), and (d-f) dominant drivers for these changes during 1982-2011. Simulations are performed with MERRA reanalyses. Only the significant trends $(p<0.05)$ are presented. Three factors, meteorological forcing, $\mathrm{CO}_{2}$ fertilization, and land use change, are considered as the potential drivers of flux trends. For each grid, the factor that generates the largest (either maximum or minimum) trend with the same sign as the net change (a-c) is selected as the driving factor. 
(a) Trend in Temperature $\left(0.28^{\circ} \mathrm{C}\right)$

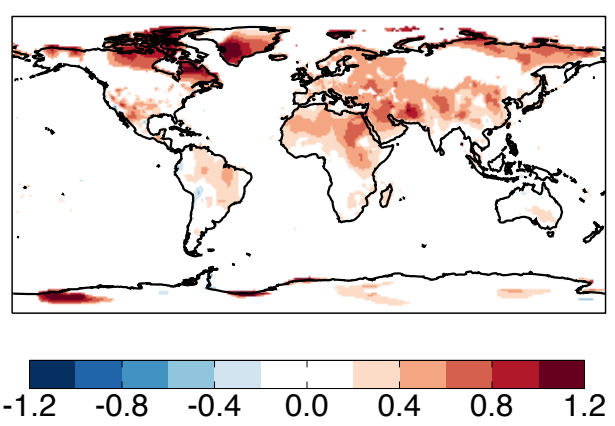

(c) Trend in specific humidity $\left(0.03 \mathrm{~g} \mathrm{~kg}^{-1}\right)$
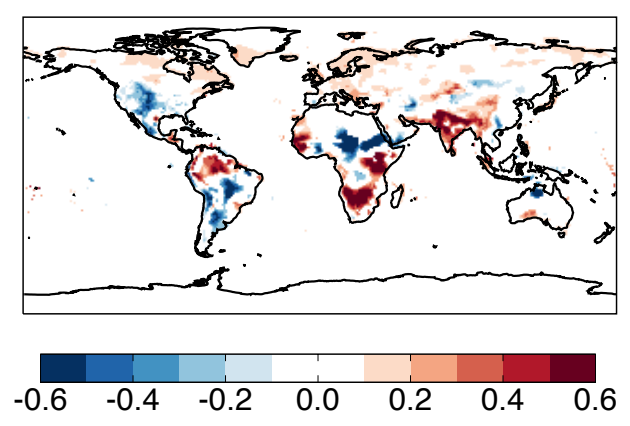

(b) Trend in PAR $\left(0.07 \mathrm{~W} \mathrm{~m}^{-2}\right)$

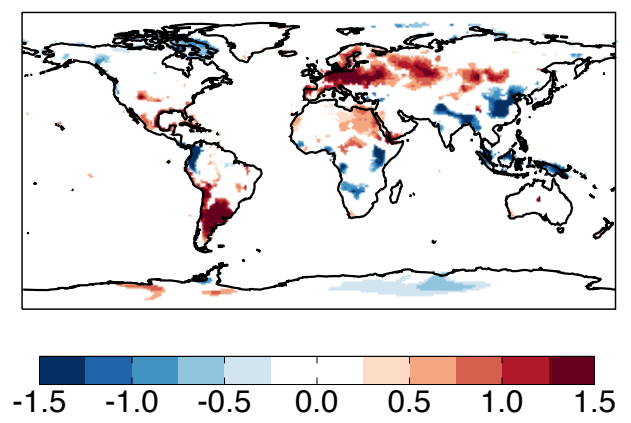

(d) Trend in soil wetness $(-0.00)$

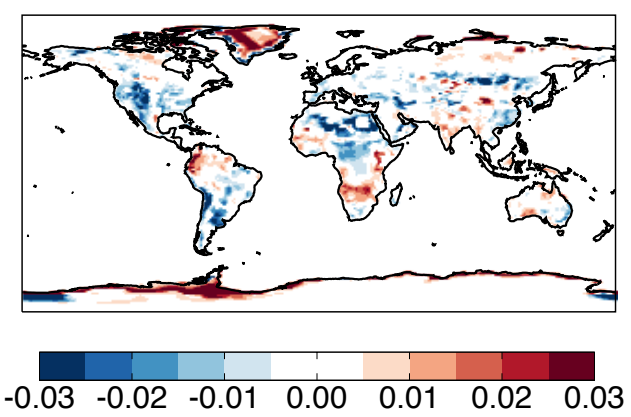

Figure S2. Trends in the annual mean (a) surface air temperature, (b) photosynthetically active radiation (PAR), (c) surface specific humidity, and (d) soil wetness at $1.5 \mathrm{~m}$ from the WFDEI reanalyses for 1982-2011. Values are shown only for trends with significance level $p<0.05$. The global average trends are shown in the title brackets. The units of trends are (a) ${ }^{\circ} \mathrm{C} \mathrm{decade}^{-1}$, (b) $\mathrm{W} \mathrm{m}^{-2}$ decade $^{-1}$, (c) $\mathrm{g} \mathrm{kg}^{-1}$ decade $^{-1}$, and (d) decade ${ }^{-1}$. 
(a) Trend in Temperature $\left(0.25^{\circ} \mathrm{C}\right)$
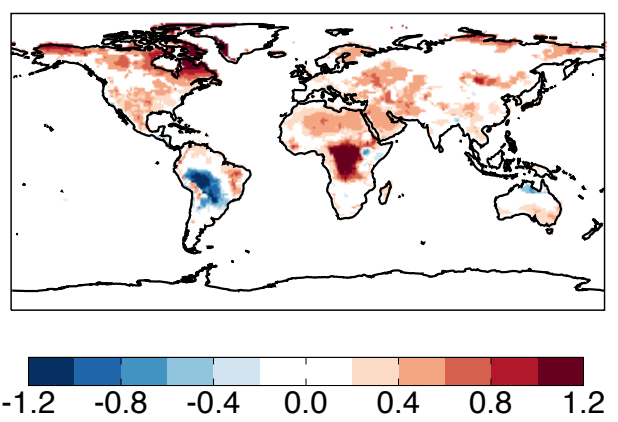

(c) Trend in specific humidity $\left(0.14 \mathrm{~g} \mathrm{~kg}^{-1}\right)$

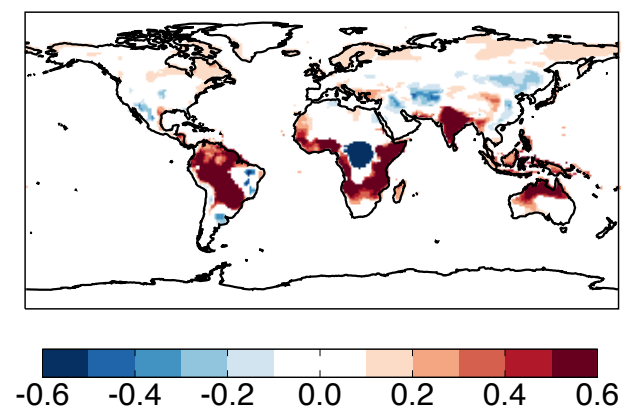

(b) Trend in PAR $\left(-0.37 \mathrm{~W} \mathrm{~m}^{-2}\right)$
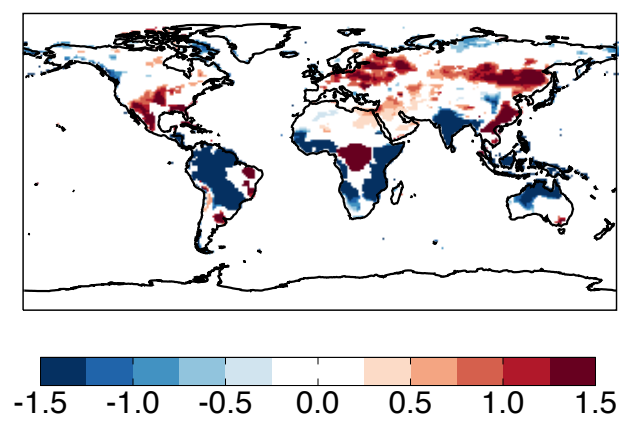

(d) Trend in soil wetness ( 0.00$)$

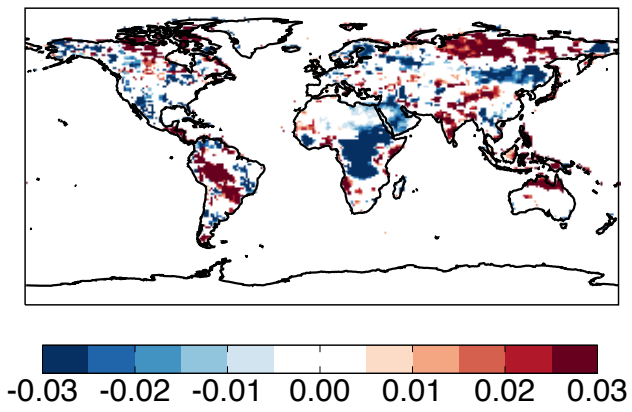

Figure S3. Trends in the annual mean (a) surface air temperature, (b) photosynthetically active radiation (PAR), (c) surface specific humidity, and (d) soil wetness at $1.5 \mathrm{~m}$ from the MERRA reanalyses for 1982-2011. Values are shown only for trends with significance level $p<0.05$. The global average trends are shown in the title brackets. The units of trends are (a) ${ }^{\circ} \mathrm{C} \mathrm{decade}^{-1}$, (b) $\mathrm{W} \mathrm{m}^{-2}$ decade $^{-1}$, (c) $\mathrm{g} \mathrm{kg}^{-1} \operatorname{decade}^{-1}$, and (d) decade ${ }^{-}$ 1. 
(a) Isoprene PS_BVOC
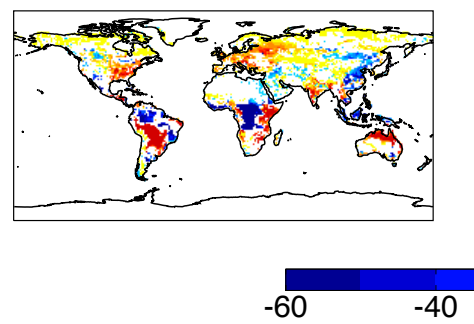

(b) Isoprene MEGAN

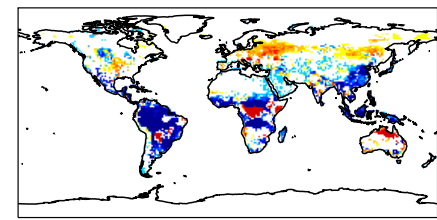

$-20$ (c) Monoterpene

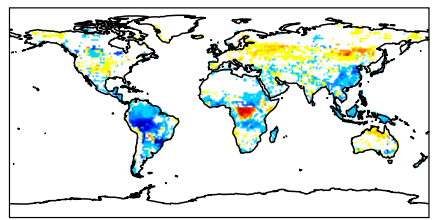

40 $60 \quad\left(\mathrm{~g} \mathrm{~m}^{-2} \mathrm{a}^{-2}\right)$

(d) Drivers of Isoprene PS_BVOC

(e) Drivers of Isoprene MEGAN

(f) Drivers of Monoterpene

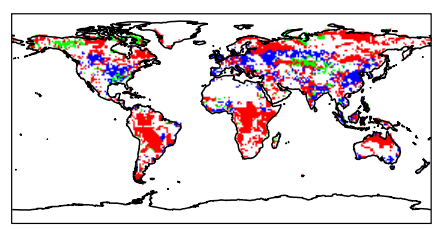

Meteorological forcing

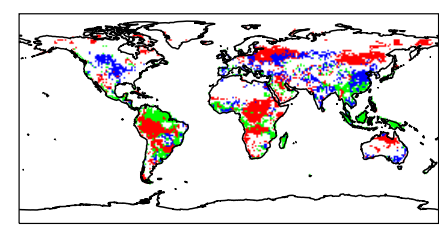

$\mathrm{CO} 2$ effect

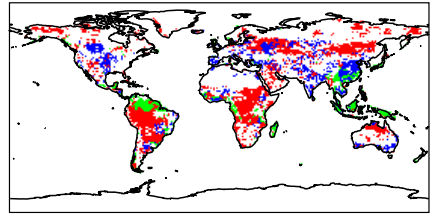

Land use change

Figure S4. Simulated trends of $(a, b)$ isoprene and (c) monoterpene, and (d-f) the dominant drivers for these changes during 1982-2011. Simulations are performed with MERRA reanalyses. Isoprene emissions are simulated with (a) PS_BVOC and (b) MEGAN schemes. Three factors, meteorological forcing, $\mathrm{CO}_{2}$ effects, and land use change, are considered as the potential drivers of flux trends. For each grid, the factor generating the largest (either maximum or minimum) trend with the same sign as the net change $(\mathrm{a}-\mathrm{c})$ is selected as the driving factor. Only significant trends $(p<0.05)$ are presented. 
(a) GPP trend of LAI_ONLY

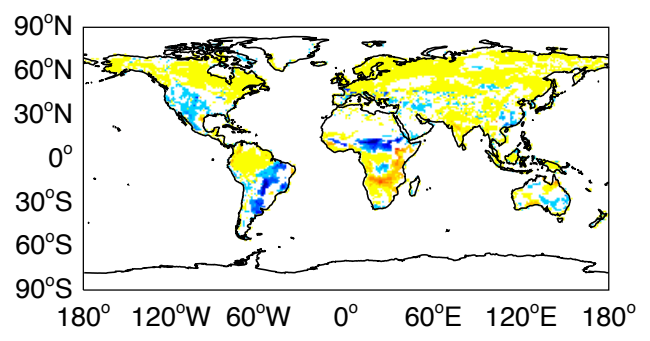

(b) GPP trend of PHEN_ONLY

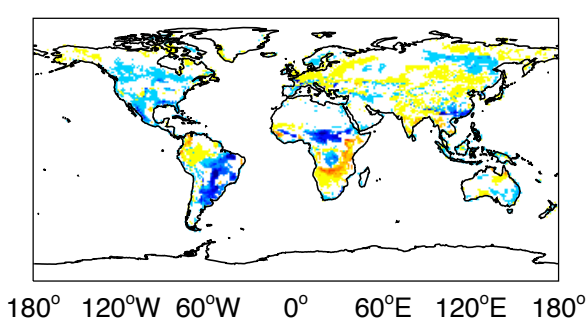

$180^{\circ} 120^{\circ} \mathrm{W} \quad 60^{\circ} \mathrm{W} \quad 0^{\circ} \quad 60^{\circ} \mathrm{E} \quad 120^{\circ} \mathrm{E} \quad 180^{\circ}$

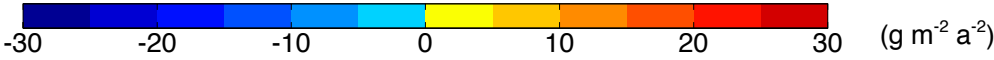

(c) NPP trend of LAI_ONLY

(d) NPP trend of PHEN_ONLY
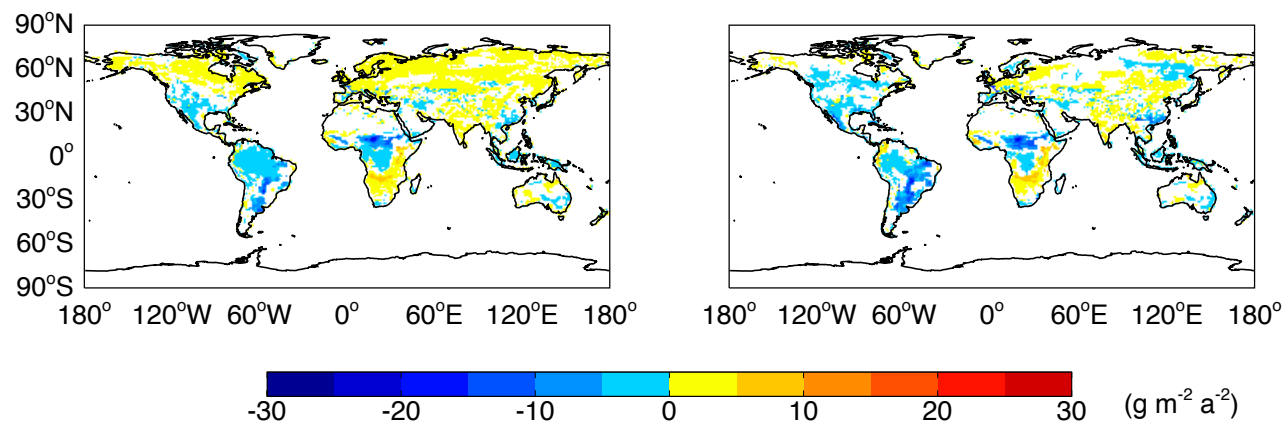

(e) Isop PS_BVOC of LAI_ONLY

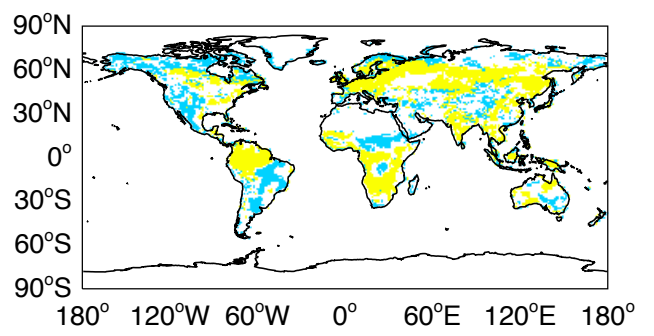

(f) Isop PS_BVOC of PHEN_ONLY
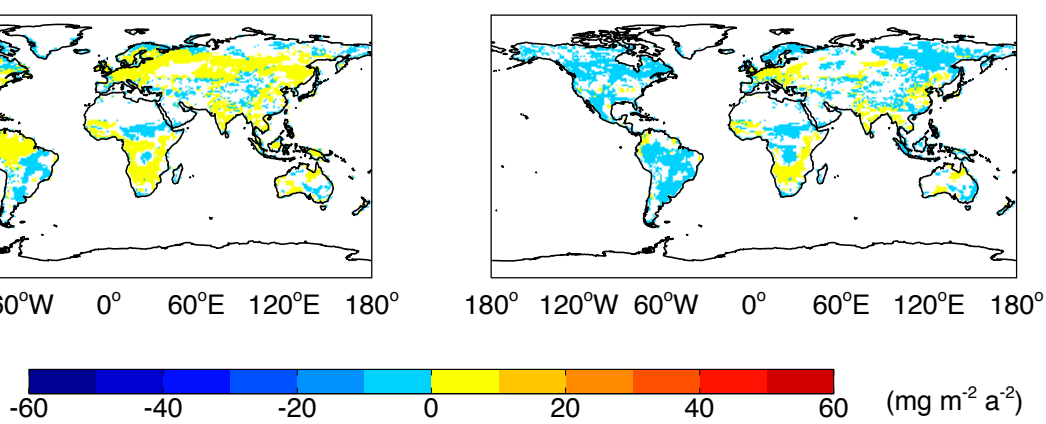

Figure S5. Predicted trends of (a, b) GPP, (c, d) NPP, and (e, f) Isoprene from PS_BVOC for 1982-2011 for simulations (a, c, e) LAI_ONLY and (b, d, f) PHEN_ONLY. Only significant trends $(p<0.05)$ are presented. Isoprene emissions with MEGAN scheme (not shown) exhibit very similar responses to LAI and phenological changes as that with PS_BVOC scheme. 
(a) Trend in spring budburst date

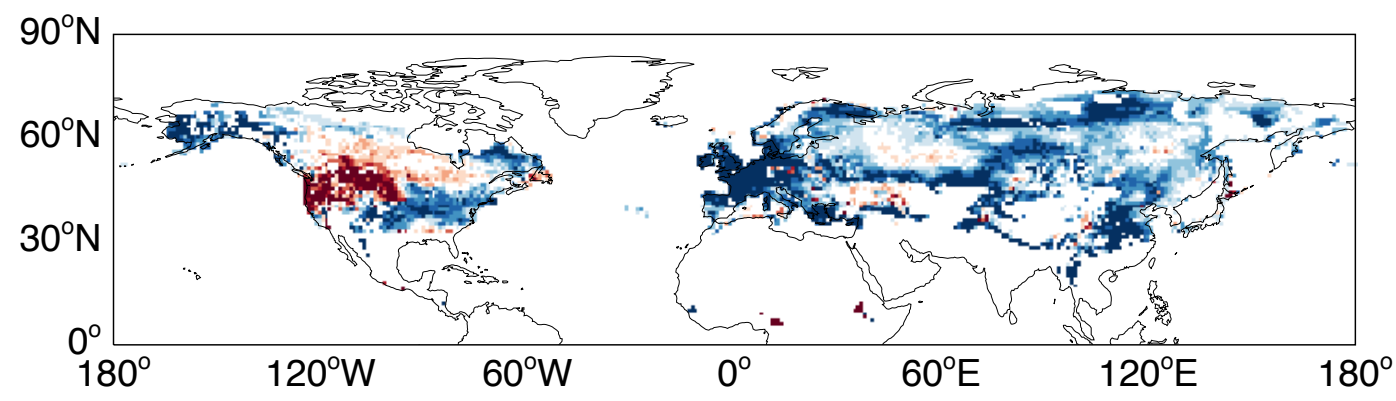

(b) Trend in autumn dormancy onset date

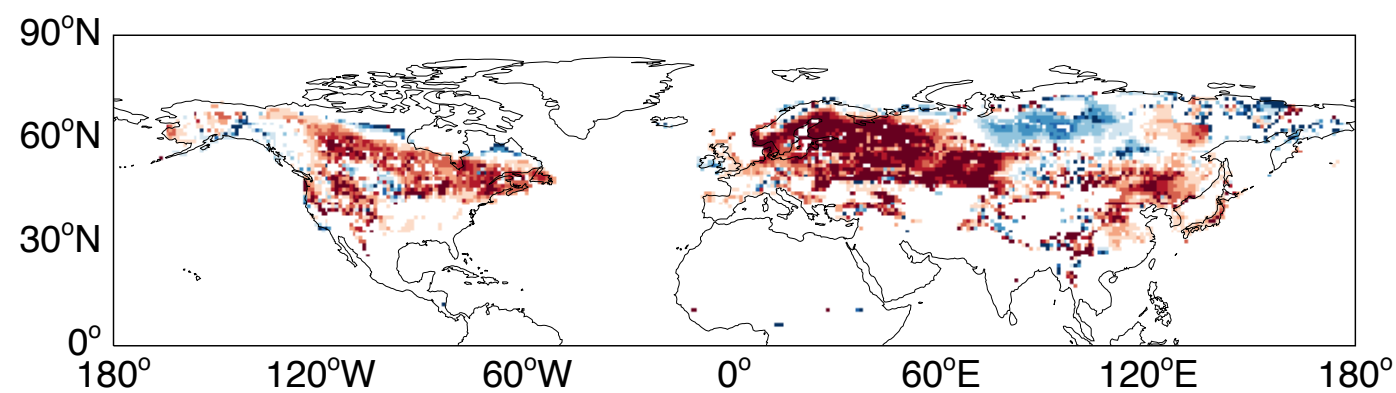

(c) Trend in growing season length

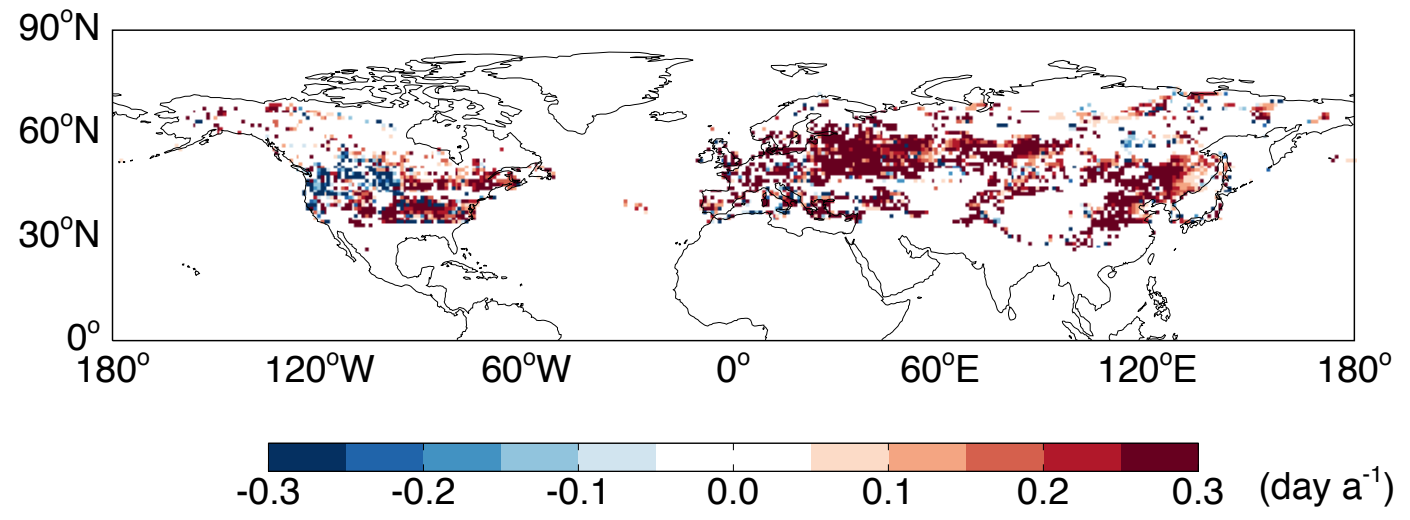

Figure S6. Predicted trends in (a) budburst date, (b) dormancy onset date, and (c) growing season length during 1982-2011. Simulated phenological dates in each grid square are the composite results from DBF, tundra, shrubland, and grassland based on PFT fraction and LAI in that grid box. Simulations are performed with WFDEI reanalysis. 
(a) Trend in JAN temperature

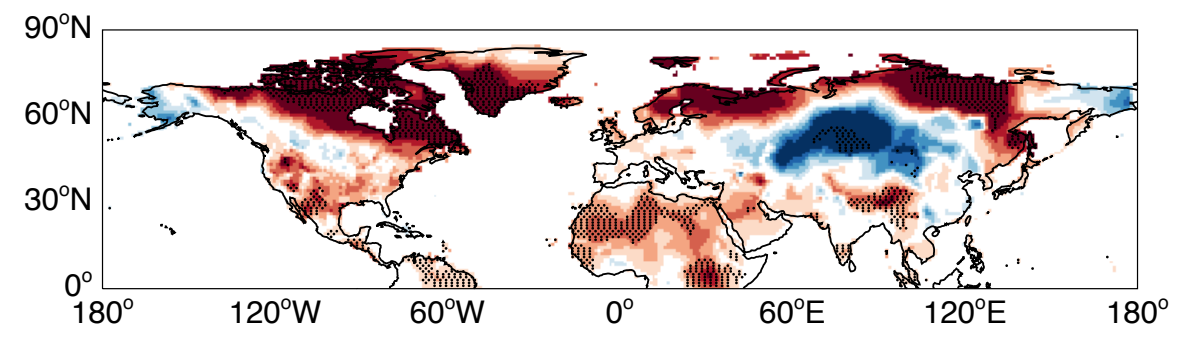

(b) Trend in APR temperature

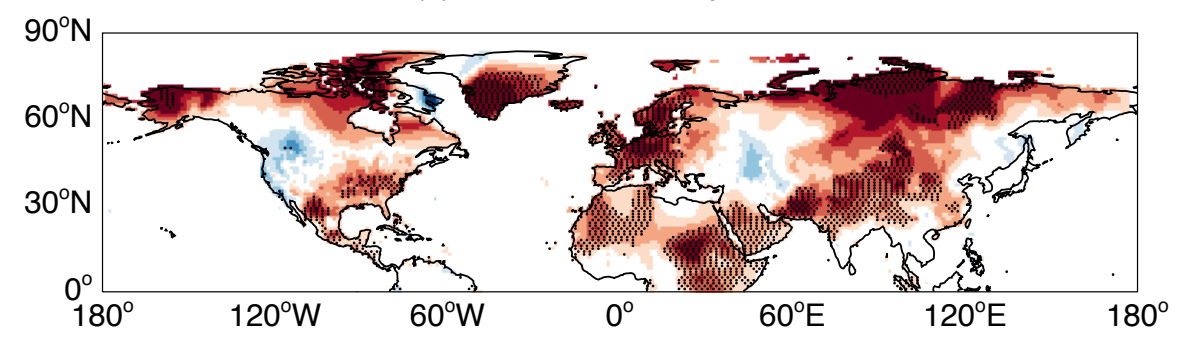

(c) Trend in SEP temperature

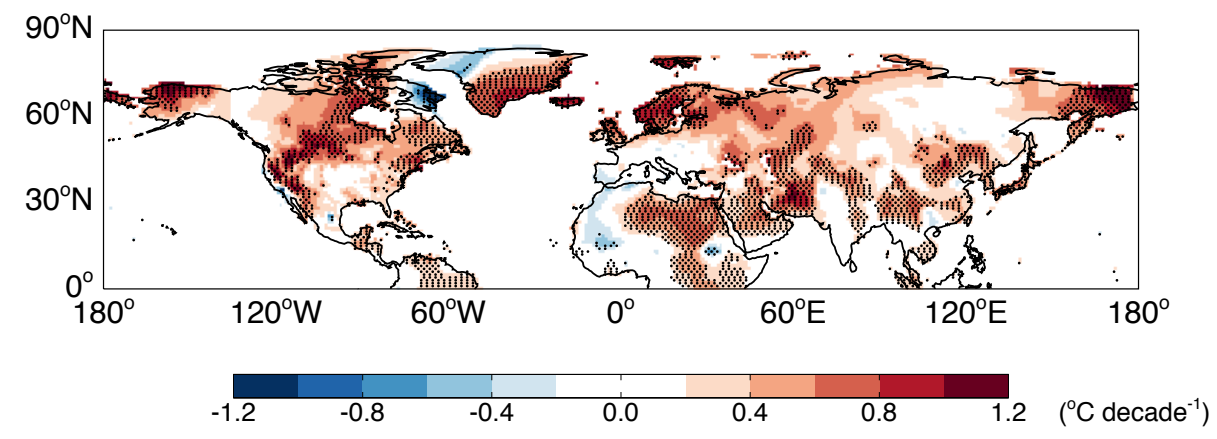

Figure 57. Trends in the surface air temperature of (a) January, (b) April, and (c) September from the WFDEI reanalyses for 1982-2011. Significant trends $(p<0.05)$ are denoted with dots. 

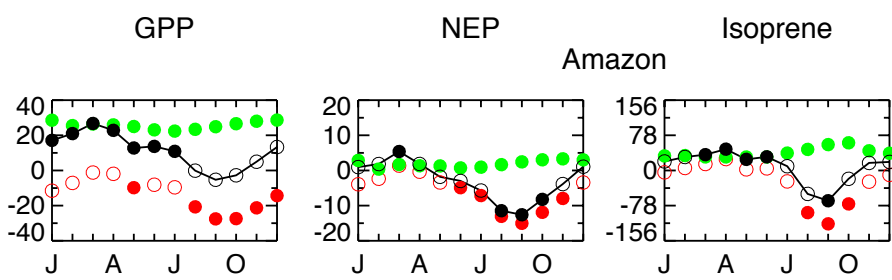

Monoterpene

North America
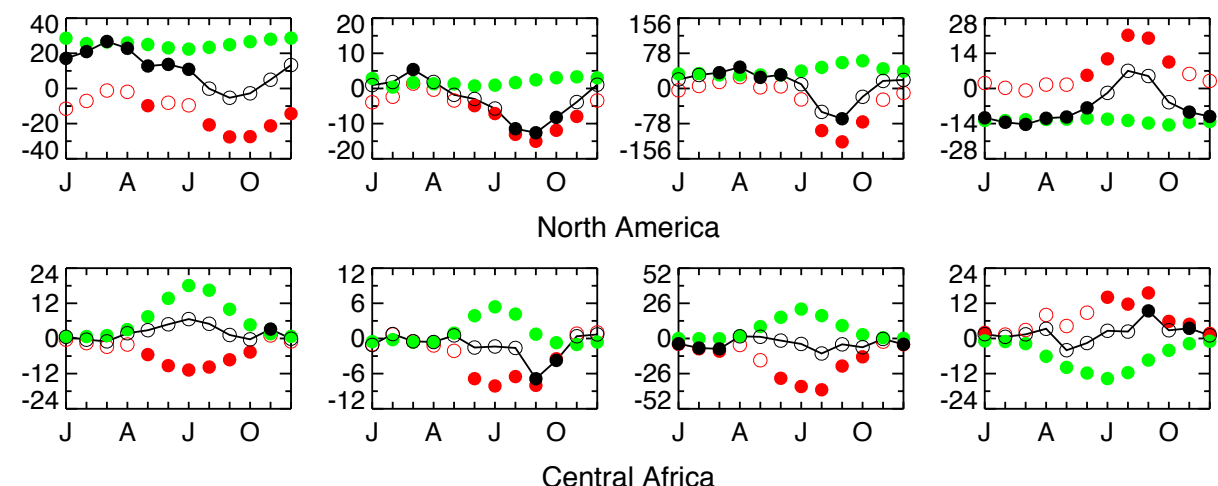

Central Africa
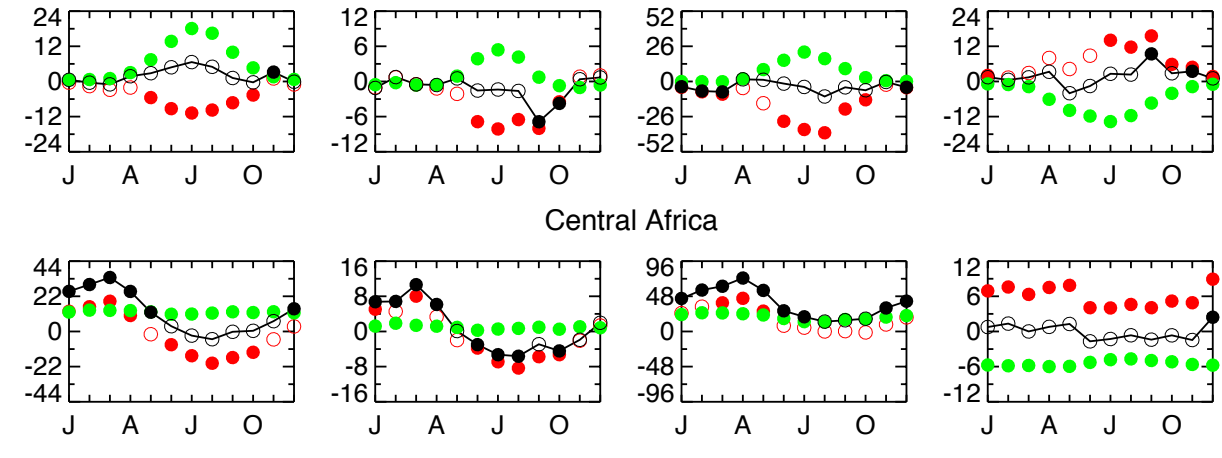

Europe
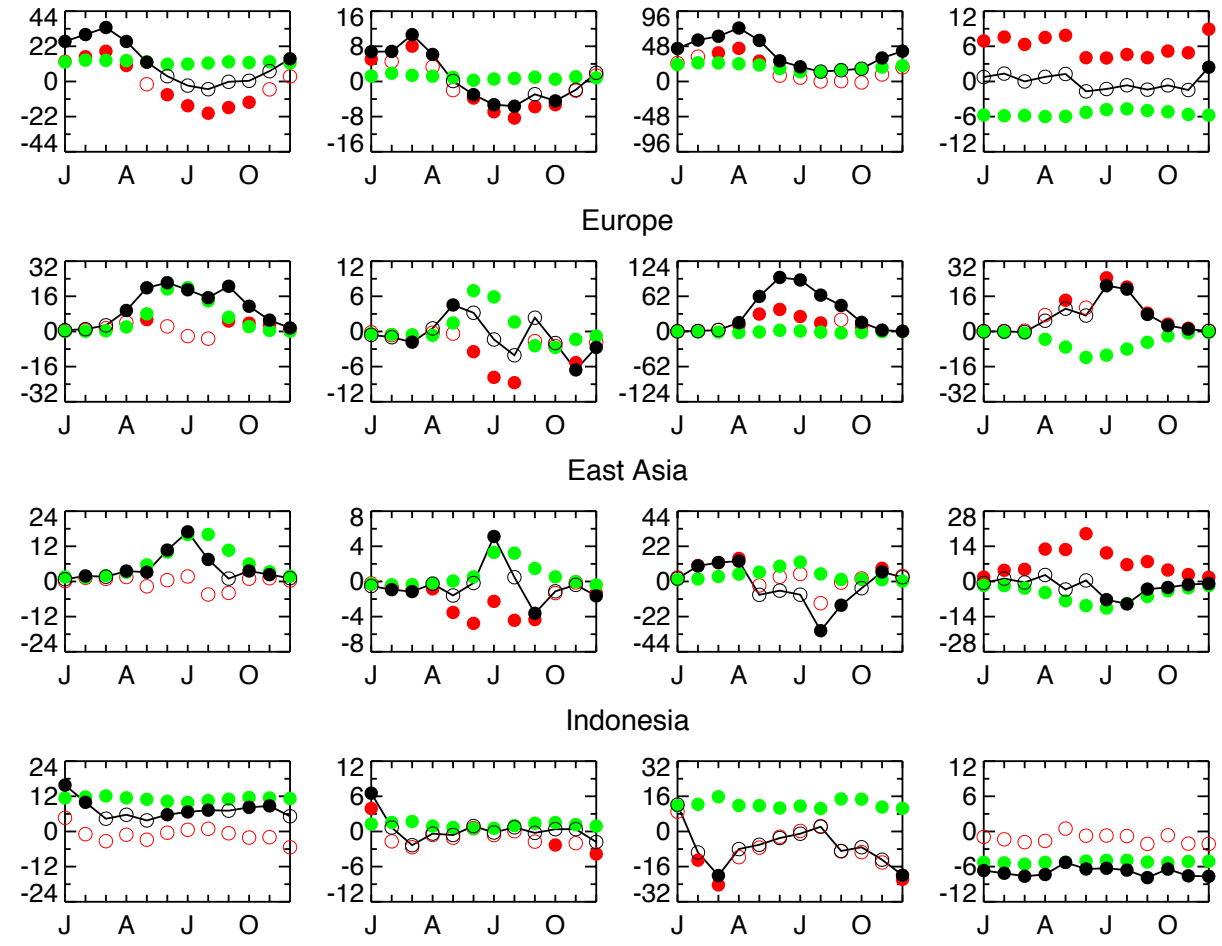

Figure S8. Simulated monthly trends and their drivers at six regions for 1982-2011. Different colors indicate simulations with all forcings (MET $+\mathrm{CO} 2$, black), meteorology alone (red), and $\mathrm{CO}_{2}$ fertilization (green). Isoprene emissions are simulated with PS_BVOC scheme. Significant trends $(p<0.05)$ are denoted with filled points and vise versa. 
(a) LAI trend from LAI3g

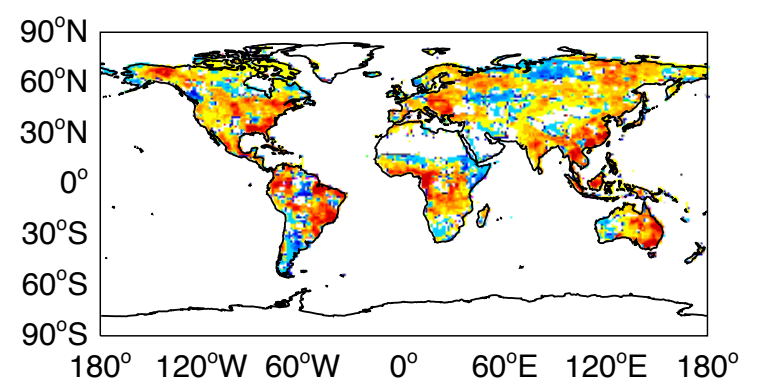

(b) LAI trend from MODIS
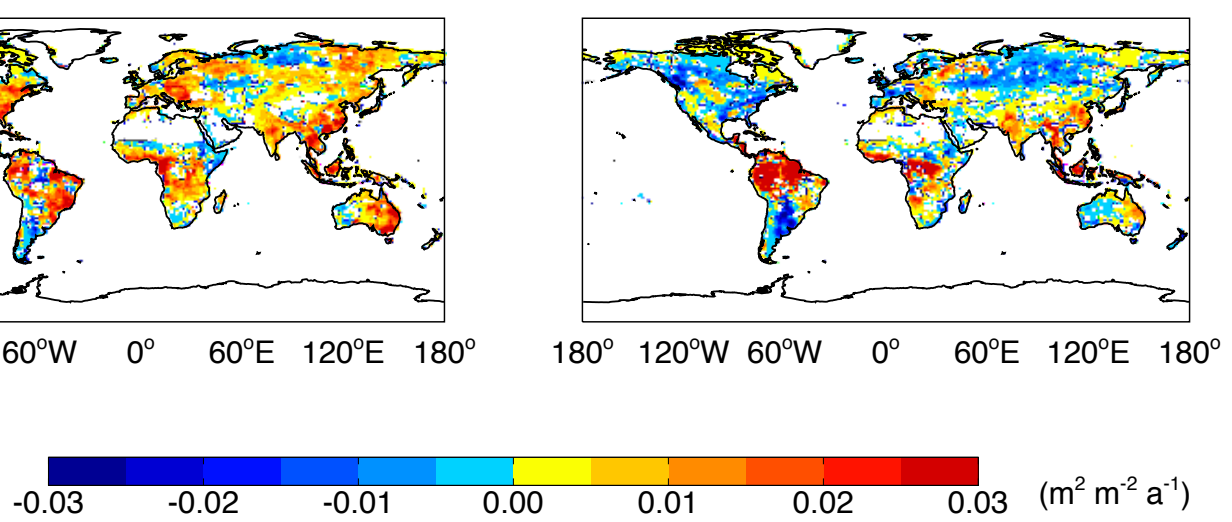

(c) GPP trend from J2009

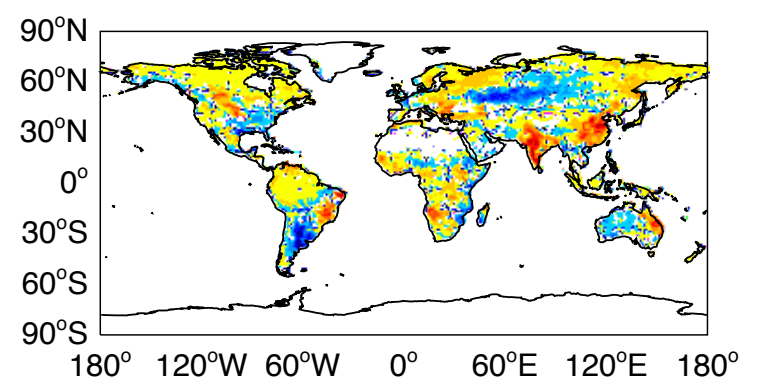

(d) GPP trend from MODIS
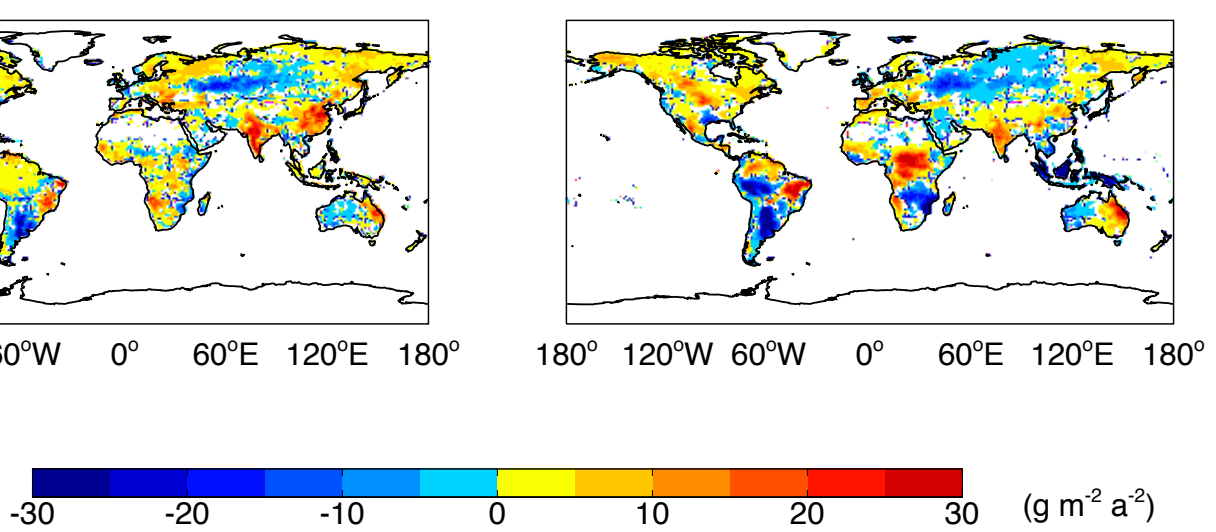

Figure S9. Comparison of observed trends in (a, b) leaf area index (LAI) and (c, d) GPP for 2000-2011 derived from different products. LAI measurements include data from (a) LAI3g retrieved based on the Normalized Difference Vegetation Index (NDVI) from Global Inventory Modeling and Mapping Studies (GIMMS) (Zhu et al., 2013) and (b) the Moderate Resolution Imaging Spectroradiometer (MODIS http://modis.gsfc.nasa.gov/). GPP measurements include data (c) upscaled from FLUXNET data with a biosphere model (Jung et al., 2009) and (d) that from MODIS (Zhao et al., 2005). Only the significant trends $(p<0.1)$ are presented. 
(a) GPP responses to $\mathrm{CO}_{2}(19.8)$

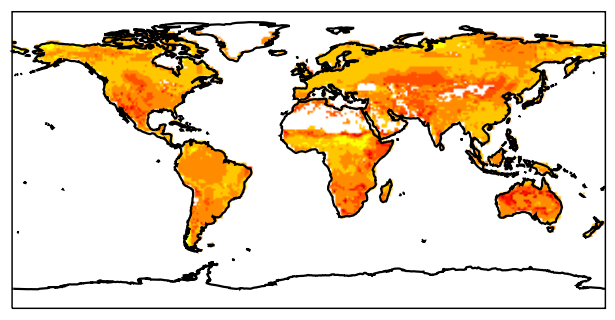

(c) Isop PS_BVOC responses to $\mathrm{CO}_{2}$ ( 8.5)

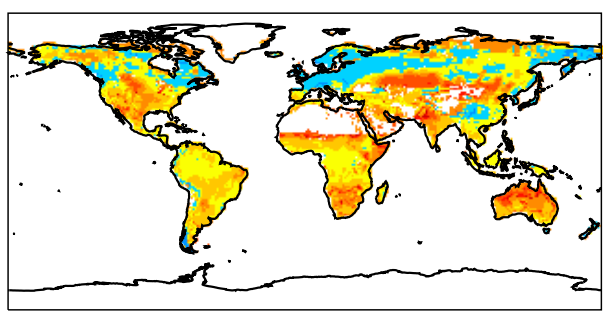

(b) NPP responses to $\mathrm{CO}_{2}(27.3)$

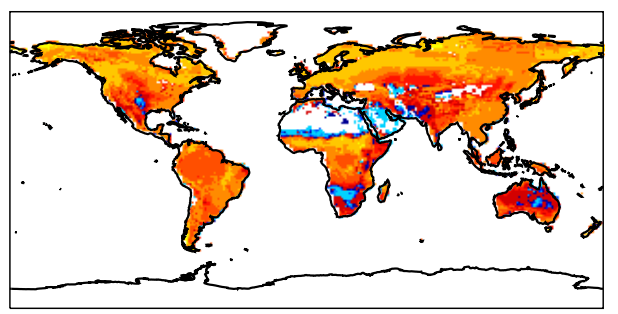

(d) Isop MEGAN responses to $\mathrm{CO}_{2}(-24.8)$

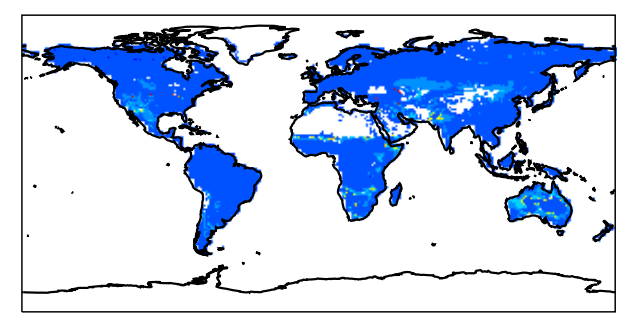

$\left(\% 100 \mathrm{ppm}^{-1}\right)$

Figure S10. Percentage changes in (a) GPP, (b) NPP, (c) PS_BVOC isoprene, and (d) MEGAN isoprene emissions in response to elevated $\left[\mathrm{CO}_{2}\right]$. At each grid square, the yearto-year total fluxes (or emissions) from simulation CO2_ONLY are linearly regressed against $\left[\mathrm{CO}_{2}\right]$ for 30 years. The ratios between the regression coefficients and the 30 -year average fluxes (or emissions) are calculated as the responses of fluxes (or emissions) to the changes in $\left[\mathrm{CO}_{2}\right]$. Only the significant $(p<0.1)$ responses are presented. The global average responses are shown in the brackets. 
(a) GPP responses to TEMP $(-0.7)$

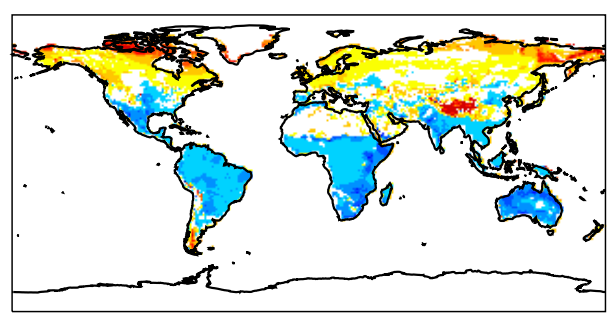

(c) Isop PS_BVOC responses to TEMP ( 1.0)

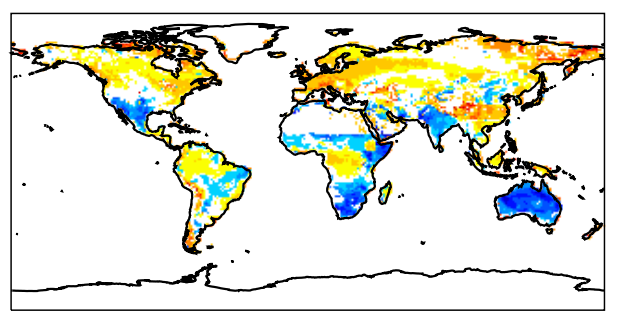

(b) NPP responses to TEMP (-3.5)

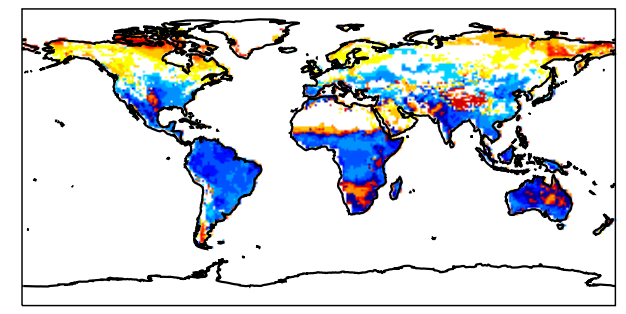

(d) Isop MEGAN responses to TEMP ( 6.8)

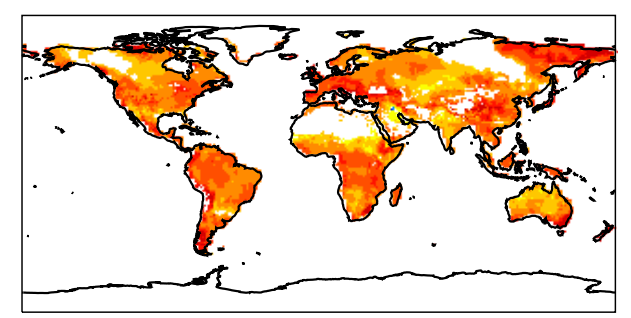

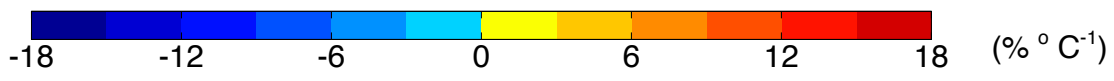

Figure S11. Similar to Fig. S10 but for responses to temperature based on simulation TEMP_ONLY. 
(a) GPP responses to PAR ( 0.3)

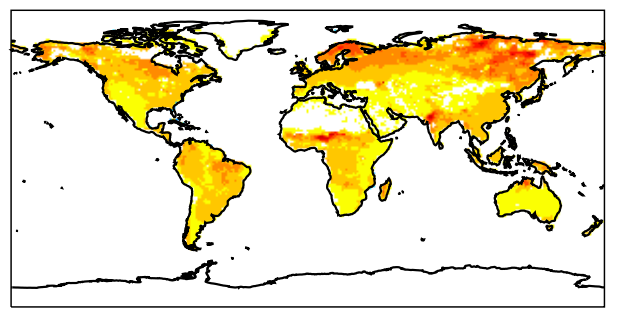

(c) Isop PS_BVOC responses to PAR ( 0.9)

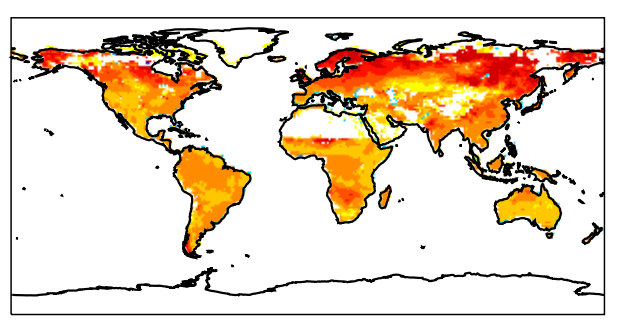

(b) NPP responses to PAR ( 0.5)

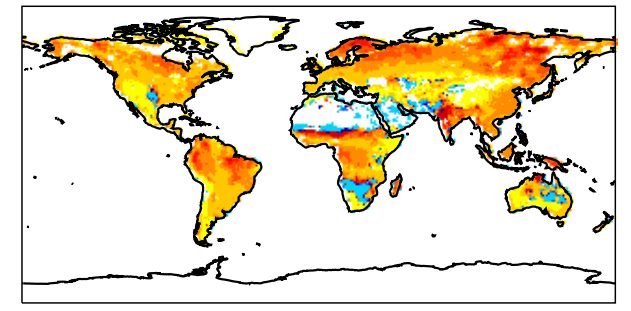

(d) Isop MEGAN responses to PAR ( 0.5)

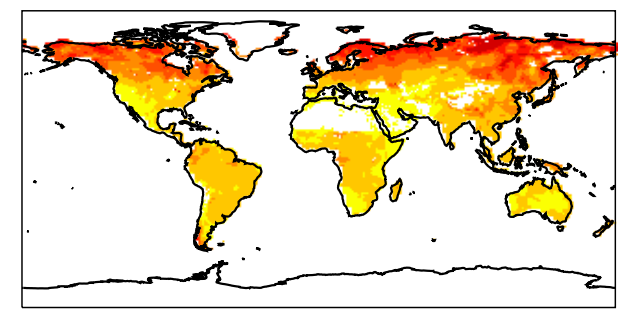

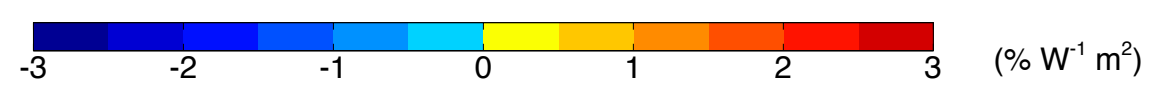

Figure S12. Similar to Fig. S10 but for responses to PAR based on simulation PAR_ONLY. 
(a) GPP responses to SOILW ( 4.7)

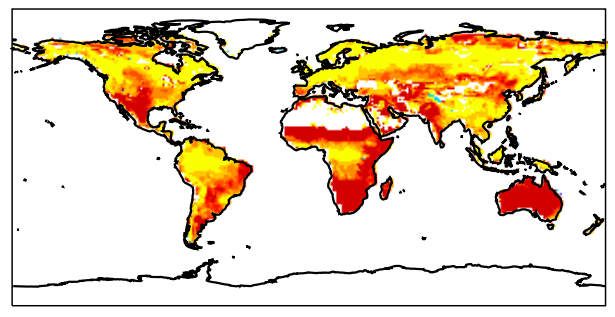

(c) Isop PS_BVOC responses to SOILW (2.9)

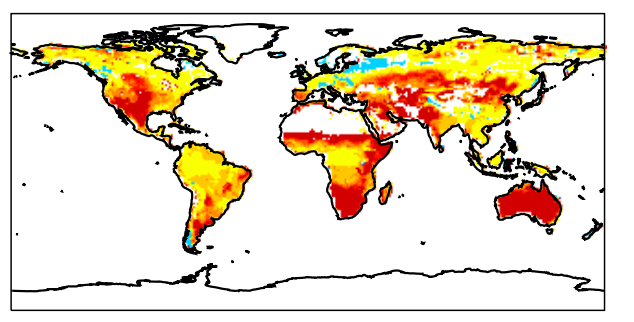

(b) NPP responses to SOILW ( 5.5)

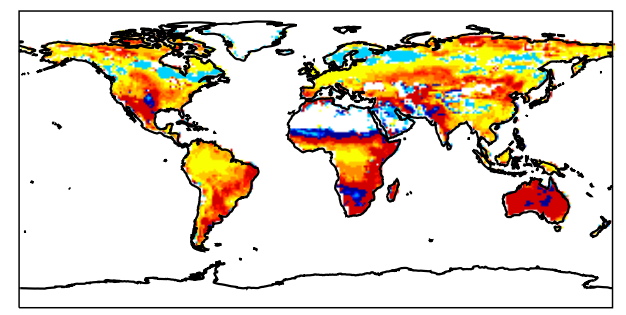

(d) Isop MEGAN responses to SOILW (1.7)

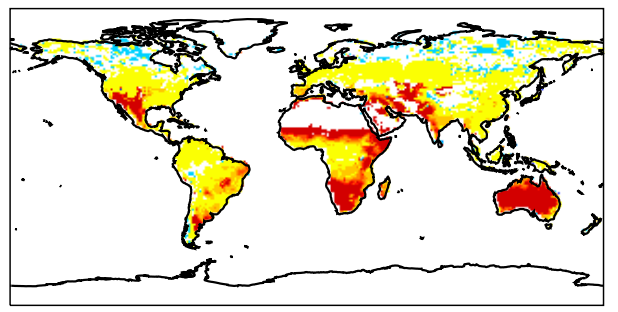

$\left(\% 0.01^{-1}\right)$

Figure S13. Similar to Fig. S10 but for responses to soil wetness at $1.5 \mathrm{~m}$ based on simulation SOILW_ONLY. 
Table S1. Summary of simulated trends of global carbon fluxes $\left(\mathrm{Tg} \mathrm{C}^{-1}\right)$ from different experiments. Simulations are using MERRA meteorology.

\begin{tabular}{cccccc}
\hline Simulations & GPP & NPP & NEP & Ra & Rh \\
\hline CO2_MET_LUC & 346 & 239.4 & 58.5 & 106.5 & 181.2 \\
CO2_ONLY & 345.1 & 250.3 & 52.6 & 94.8 & 199.7 \\
MET_ONLY & 16.1 & -1.6 & -3.7 & 17.6 & 3.3 \\
LUC_ONLY & -12.8 & -8.1 & -27.2 & -4.6 & 21.5 \\
TEMP_ONLY & -7.5 & -38.6 & 21 & 31.1 & -56.6 \\
PAR_ONLY & -11.4 & -9.1 & -9.1 & -2.4 & 2.7 \\
SOILW_ONLY & -94.9 & -52.5 & -13.5 & -42.4 & -37.2 \\
\hline
\end{tabular}




\section{References}

Jung, M., Reichstein, M., and Bondeau, A.: Towards global empirical upscaling of FLUXNET eddy covariance observations: validation of a model tree ensemble approach using a biosphere model, Biogeosciences, 6, 2001-2013, 2009.

Zhao, M. S., Heinsch, F. A., Nemani, R. R., and Running, S. W.: Improvements of the MODIS terrestrial gross and net primary production global data set, Remote Sens Environ, 95, 164-176, doi:10.1016/J.Rse.2004.12.011, 2005.

Zhu, Z. C., Bi, J., Pan, Y. Z., Ganguly, S., Anav, A., Xu, L., Samanta, A., Piao, S. L., Nemani, R. R., and Myneni, R. B.: Global Data Sets of Vegetation Leaf Area Index (LAI) $3 \mathrm{~g}$ and Fraction of Photosynthetically Active Radiation (FPAR)3g Derived from Global Inventory Modeling and Mapping Studies (GIMMS) Normalized Difference Vegetation Index (NDVI3g) for the Period 1981 to 2011, Remote SensBasel, 5, 927-948, doi:10.3390/Rs5020927, 2013. 